\title{
COMPUTATIONAL MODELLING OF RADIOFREQUENCY CARDIAC ABLATION TO STUDY THE EFFECT OF COOLING ON LESION PARAMETERS
}

\author{
Carolyn Berkmortel, Hamed Avari, Eric Savory \\ Department of Mechanical and Materials Engineering \\ University of Western Ontario \\ London, Ontario \\ cberkmor@uwo.ca
}

\begin{abstract}
Radiofrequency ablation (RFA) is a technique used to treat cardiac arrhythmias. It creates lesions in the heart by creating thermal damage. Due to limitations associated with in vivo as well as in vitro studies, computational methods assist in further analysis of the problem by allowing for quicker and more diverse parametric studies and hence, a more thorough understanding of the physics involved. These computational models have been proven to be good representations of the process by accurately modelling the catheter with simplified geometry and boundary conditions. Although these studies have inconsistencies in material properties (due to the variation of thermal and mechanical properties in biological tissue) as well as different methods of creating the geometry and applying the boundary conditions, overall they are quite similar. The effects of esophageal cooling were investigated to understand its effect on the process. It was determined that using the standard model found within the literature, the esophageal cooling changed the lesion depth by less than $18 \%$, while changing the maximum tissue temperature by as much as $13.4 \%$.
\end{abstract}

Keywords: Biomedical, simulation, computational fluid dynamics

\section{INTRODUCTION}

Radiofrequency ablation (RFA) is used in patients to treat cardiac arrhythmias (a cardiovascular disorder involving irregular heart rhythm). Atrial fibrillation, the most common type of cardiac arrhythmia, is where the atrial electrical signal is chaotic. This condition can be life threatening and must be treated [1]. For the past decade RFA has been the most common and effective method for treating atrial fibrillation that is resistant to drug treatment [2]. In this procedure, the tissue surrounding the pulmonary arteries is heated by a radiofrequency current (causing joule heating in the tissue) until the tissue is permanently damaged and a lesion is formed. This process isolates the incorrect electrical signals that originate there, so normal heart electrical function can resume $[3,4]$. One of the risks of this process is the development of an atrialesophageal fistula. This is a rare (it only occurs in less than $1 \%$ of patients after RF procedures) but serious condition that can potentially result in a patient's death [5]. Atrial-esophageal fistula is caused by thermal damage to the esophagus; however, the exact mechanism of injury is not yet well understood [6]. Studies have been conducted, both experimentally and computationally, to further understand the heat transfer in RF ablation, but there are still many unknowns regarding how thermal damage to the esophagus occurs and how it can be prevented.

\section{LITERATURE REVIEW}

The first RFA study [7] employed a 2-D axially symmetric mathematical model but no computational simulations were conducted. The first models with a geometric domain that discretized the equations for voltage and temperature distribution (that were solved by a computer program) were based on 2-D geometry [8-10]. Experiments were conducted in these studies to determine convective heat transfer coefficients in the heart as well as the heart tissue properties [8-10]. Much of the subsequent research drew heavily on this initial work for geometry, tissue properties and convection coefficients for blood flow in the heart, notably Berjano and co-workers $[4,11$ 14]. A proven computational model strategy has emerged from the research and several aspects of that model will be considered in detail here.

\section{A. Geometry}

The geometry of these models varies, as each study considers a different situation, or models a specific experiment. Most studies model the catheter as a cylinder with a hemispherical tip. The catheter diameter is specified in French (where $1 \mathrm{Fr}=1 / 3 \mathrm{~mm}$ ), ranging from 6-8 Fr, whilst the length ranges from $3-5 \mathrm{~mm}$. The catheter is modelled partially embedded into the tissue in almost every scenario, with only one study accounting for tissue deformation [15]. Above the tissue is the blood, which is sometimes modelled and sometimes excluded (see blood modeling section for more information). The overall size of the model is determined through a Cauchy independence test which involves seeking the smallest domain possible without affecting the results. For most studies, the overall size of the domain is less than a cube with $80 \mathrm{~mm}$ sides. Studies often use axial symmetry or face symmetry. Axial 
symmetry cases cannot model blood flow and must use convection coefficients, but computation time is reduced significantly.

Most studies consider the orientation of the catheter to be perpendicular or parallel to the tissue. One study has considered the effect of catheter angle on lesion size and found that the parallel orientation produces smaller lesions [16], and so, for the purposes of finding the maximal lesion size, the perpendicular orientation is recommended. When the catheter is perpendicular to the tissue, the depth of the catheter into the tissue must be considered. In most studies, the depth used comes from previous research or is obtained from experimental measurements of ablated tissue. Currently, there is one experimental study relating catheter force to tissue depth [17].

The final parameter that varies in the model geometries is tissue thickness. In humans, the myocardium thickness in the posterior wall of left atrium is not uniform and varies from patient to patient. Therefore, it would be expected to vary in models as well. Many studies use very thick and unrealistic myocardial thicknesses to ensure that the bottom boundary condition does not affect the lesion size. For example, one recent study uses $20 \mathrm{~mm}$ thickness [4] in place of modelling multiple layers of tissue which would complicate the model. Some studies do include other layers, such as fat and esophageal layers, instead of using an unrealistically thick myocardium thickness $[5,18]$.

\section{B. Governing Equations}

The governing equations are consistent across all of the literature. The Bioheat equation is used in conjunction with Laplace's equation to take into account joule heating in the tissue and to give accurate temperature distributions. Fluid flow (if included) is governed by the continuity equation and the laminar, incompressible Navier-Stokes equations. For several studies, the vaporization of tissue is included. To account for the vaporization, the latent heat is included as the latent heat of water and there are different properties for the liquid and gaseous forms of tissue. It has been noted by some researchers that this method is inaccurate and should not be used. Instead, the focus should be on keeping the temperatures below the vaporization temperature of water, $100^{\circ} \mathrm{C}$ [19]. For most studies heat loss caused by blood perfusion and the metabolic heat generation terms in the Bioheat equation are negligible and, hence, neglected [7].

\section{Catheter Boundary Conditions}

The boundary conditions on the tip of the electrode vary in the present models. The types of boundary conditions used are: constant temperature, constant temperature through voltage regulation, constant voltage, constant power through voltage regulation, and constant maximum tissue temperature through voltage regulation. In addition to these five boundary conditions, the catheter may be modeled with or without saline irrigation (depending on the type of catheter modelled). The irrigated catheters slightly change the geometry of the model but leave most parameters and boundary conditions unchanged as they simply add another inlet to the blood flow. Irrigated catheters are more clinically relevant at the present time [4].
Applying a constant voltage boundary condition to model a constant power ablation is shown to be an acceptable approximation with a relatively high accuracy. However, if constant voltage is used, then other parameters are in a state of flux which affects how the lesion develops over time. For this reason, a constant voltage boundary condition is not always used. The next most common boundary condition is using voltage regulation to hold either temperature or power constant. In order to model these boundary conditions, the voltage applied at the active electrode must be regulated through a control feedback loop. These changing boundary conditions are implemented through the use of software modifications such as MATLAB integration into the program ANSYS, user defined functions (udfs) within the program, or other program macros [4].

\section{Modelling The Effect of Blood}

Most of the modelling research uses experimental measurement to determine the convective coefficient in the myocardium. Then, they apply a convective boundary condition to the tissue surface rather than modelling actual blood flow. The main methods to model blood flow in RFA include: using convection coefficients excluding the blood from the model; using convective coefficients with the blood included in the model (stagnant); the same as the previous method but with temperature-dependent blood conductivity; and, finally, modelling the blood flow itself. Interestingly, no study has yet included pulsating or turbulent blood flow (or both) in their model. The studies that use convection coefficients do take into account these parameters, often averaging the high and low turbulent blood flow conditions [8]. Most papers use a similar method. In future work, it is recommended to investigate a more accurate representation of the actual blood flow in the heart by studying the effects of pulsatile flow and turbulence.

\section{E. Other Boundary Conditions}

For all models, the boundary conditions other than the electrode and blood boundary condition are the same. There is a specified temperature at all surfaces far away from the electrode, which varies from $37.5^{\circ} \mathrm{C}$ to $36^{\circ} \mathrm{C}$. There, zero electrical flux is specified on all the walls and surfaces. The bottom surface is the only one that is different with a specified temperature and a specified voltage of $0 \mathrm{~V}$ to mimic the effect of the grounding pad. All of the studies for RFA in the heart that were reviewed here, used these boundary conditions except for one, which studied the effect of using a cooling balloon in the esophagus to prevent thermal injury [5]. This study applied a convective boundary condition to the bottom face (where the esophagus is located) rather than a prescribed temperature. This is the only study of that kind and is a potential method of preventing atrial-esophageal fistula. The aspect of esophageal cooling is one that needs further investigation. Overall, one may trust that these standard boundary conditions are justified in their use and produce accurate lesion sizes.

\section{F. Material Properties}

The material properties, like density, viscosity and thermal conductivity, used in these models represent one of the greatest differences between the different models [20]. Tissue properties are very variable and inconsistent and so any material property 
introduces error in the results. There have been several studies examining the effect of material properties on the results obtained [21-25], including changing thermal and electrical conductivity as well as determining how those conductivities should be changed as temperature changes in the model. Material properties, such as myocardial density, and blood properties, including density, viscosity, electrical conductivity, and thermal conductivity, are important, but they can be taken from previous studies or reliable sources as they do not greatly affect lesion size [22]. Some models have also included tissue vaporization while others have ignored it, or limited the tissue temperatures to below the vaporization point of $100^{\circ} \mathrm{C}$. In two recent cardiac studies $[4,26]$ the vaporization is taken into account with the following equation.

$$
\frac{\partial(\rho h)}{\partial t}=\frac{\partial T}{\partial t} \cdot\left\{\begin{array}{cr}
\rho_{l} c_{l}, & 0 \leq T \leq 99^{\circ} \mathrm{C} \\
H_{f g} C, & 99<T \leq 100^{\circ} \mathrm{C} \\
\rho_{g} c_{g}, & T>100^{\circ} \mathrm{C}
\end{array}\right.
$$

$\rho_{\mathrm{i}}=$ density of tissue phase $\left(\mathrm{kgm}^{-3}\right)$

$\mathrm{c}_{\mathrm{i}}=$ specific heat $\left(\mathrm{Jkg}^{-1} \mathrm{~K}^{-1}\right)$

$\mathrm{H}_{\mathrm{fg}}=$ latent heat $\left(\mathrm{Jkg}^{-1}\right)$

$\mathrm{C}=$ tissue water content $(\%)$

$\mathrm{i}=l$ corresponds to the liquid tissue phase

$\mathrm{i}=g$ corresponds to the gaseous tissue phase

It was found that the equations chosen to model material properties do not affect lesion diameter significantly [22]. To achieve accurate results the thermal and electrical tissue conductivities must be temperature-dependent, following one of the equations in the in Table 1 in [22]. The tissue properties vary across studies, but the effect on the results appears to be minimal so long as the tissue properties are made temperaturedependent in some way [22]. A 3.5\% maximum difference in final lesion size was found between identical models with different material properties [22].

\section{G. Lesion Size Measurement}

In the beginning of RFA modelling the Arrhenius thermal damage equation was used to calculate the lesion size [7,9,27]. This equation suggests, for heart tissue, a thermal damage temperature of greater than $48.9^{\circ} \mathrm{C}$ [28]. After this general temperature limit had been established and confirmed [7,9,27], most papers merely used an arbitrarily selected isotherm to measure lesion size because of its simplicity. The majority of studies use a $50^{\circ} \mathrm{C}$ isotherm. The $50^{\circ} \mathrm{C}$ isotherm has been tested many times and is shown to be a consistent and accurate measurement for the lesion size created.

Having reviewed the literature concerning RFA modelling, the present work seeks to use the best available strategy to examine the influence of key parameters on the performance of a non-irrigated RFA catheter and investigate the effect of esophageal cooling.

\section{Non-IRrigated CAtheter Ablation Model}

In the present work an improved model was created to examine effect of esophageal cooling. The geometry of González-Suárez and Berjano [26] was replicated, the same governing equations and material properties were used and, at first, all the same boundary conditions were implemented so

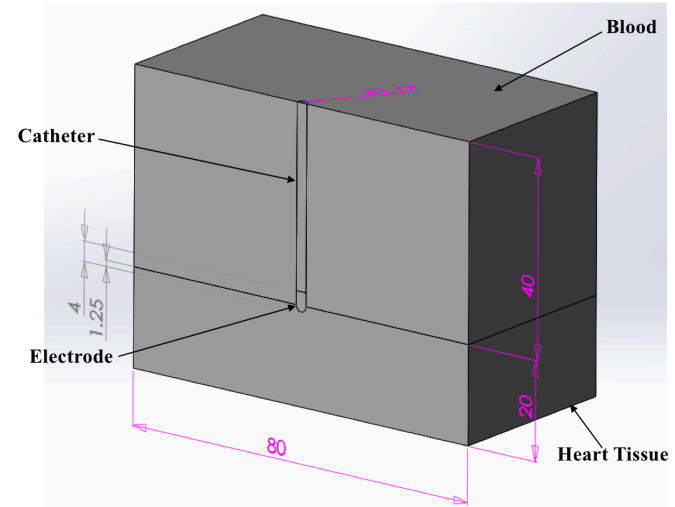

Figure 1. Geometry for non-irrigated catheter model. Dimension not shown is the depth which is $40 \mathrm{~mm}$.

that the present model could be validated. Following this the effect of convective cooling was studied on the bottom face. This study was then repeated with subsequent models that had the same geometry as the first, except for a smaller myocardial thickness to better represent the real-life situation.

\section{A. Geometry}

The geometry, shown in Fig. 1, consists of a $7 \mathrm{Fr}-4 \mathrm{~mm}$ (d $=2.33 \mathrm{~mm}, \mathrm{~L}=4 \mathrm{~mm}$ ) cylindrical catheter with a hemispherical tip embedded $1.25 \mathrm{~mm}$ into myocardial tissue whose thickness, $\mathrm{H}$, was varied from $20 \mathrm{~mm}$ to $10 \mathrm{~mm}$ and then $5 \mathrm{~mm}$. The overall domain of the model was the same as González-Suárez and Berjano's [26] who obtained those dimensions by means of a convergence test. Symmetry was used to reduce computation time. The model by González-Suárez and Berjano [26] included a thermistor embedded in the catheter to measure the overall temperature of the catheter and regulate the voltage to maintain constant temperature, but this was excluded from the present model as it was an unnecessary complication.

\section{B. Governing Equations and Material Properties}

The governing equations for this model are as discussed above and the material properties in Table I were used. For this tissue, $\mathrm{H}_{\mathrm{fg}}=2.162 \mathrm{Jm}^{-3}, \mathrm{C}=75 \%$, and $\rho_{\mathrm{l}}=958 \mathrm{kgm}^{-3}\left(\right.$ at $\left.100^{\circ} \mathrm{C}\right)$ [26], so the vaporization latent heat is $2257 \mathrm{~kJ} \mathrm{~kg}^{-1}$. The equations were implemented in ANSYS Fluent v18.2 by udfs. The viscosity of blood was set to $0.0021 \mathrm{kgm}^{-1} \mathrm{~s}^{-1}$.

TABLE I. MATERIAL PROPERTIES USED IN NON-IRRIGATED MODEL

\begin{tabular}{|c|c|c|c|c|}
\hline & $\begin{array}{c}\text { Density, } \boldsymbol{\rho} \\
\left(\mathbf{k g m}^{-3}\right)\end{array}$ & $\begin{array}{c}\text { Specific } \\
\text { Heat, c } \\
\left(\mathbf{J k g}^{-1} \mathbf{K}^{-1}\right)\end{array}$ & $\begin{array}{c}\text { Thermal } \\
\mathbf{C o n d . ,} \mathbf{k} \\
\left(\mathbf{W m}^{-1} \mathbf{K}^{-\mathbf{1}}\right)\end{array}$ & $\begin{array}{c}\text { Elec. } \\
\mathbf{C o n d . ,} \boldsymbol{\sigma} \\
\left(\mathbf{S m}^{-1}\right)\end{array}$ \\
\hline Catheter & 70 & 1045 & 0.026 & $1 \times 10^{-5}$ \\
\hline Electrode & 21500 & 132 & 71 & $4.6 \times 10^{6}$ \\
\hline Blood & 1000 & 4180 & 0.541 & 0.667 \\
\hline Tissue & $\begin{array}{c}l-1060 \\
g-370.44\end{array}$ & $\begin{array}{c}l-3111 \\
g-2155.92\end{array}$ & $\begin{array}{c}\text { See } \\
\text { Equation 2 }\end{array}$ & $\begin{array}{c}\text { See } \\
\text { Equation 3 }\end{array}$ \\
\hline
\end{tabular}

$$
\begin{gathered}
k(T)=\left\{\begin{array}{cc}
0.531+0.0012(T-37), & 0<T \leq 100^{\circ} \mathrm{C} \\
0.606, & T>100^{\circ} \mathrm{C}
\end{array}\right. \\
\sigma(T)=\left\{\begin{array}{cc}
0.541 e^{0.015(T-37)}, & 0<T \leq 100^{\circ} \mathrm{C} \\
1.3-0.274(T-100), & 100<T \leq 105^{\circ} \mathrm{C} \\
1.371 \times 10^{-4}, & T>105^{\circ} \mathrm{C}
\end{array}\right.
\end{gathered}
$$


TABLE II. COMPARISON OF RESULTS OBTAINED WITH VARIOUS BOTTOM BOUNDARY CONDITIONS

\begin{tabular}{|c|c|c|c|c|c|}
\hline $\begin{array}{c}\text { Boundary } \\
\text { Condition On } \\
\text { Bottom Face }\end{array}$ & $\begin{array}{l}\text { Lesion } \\
\text { Depth } \\
(\mathrm{mm})\end{array}$ & $\begin{array}{l}\text { Lesion } \\
\text { Width } \\
\text { (mm) }\end{array}$ & $\begin{array}{c}\text { Max } \\
\text { Blood } \\
\text { Temp } \\
\left({ }^{\circ} \mathrm{C}\right) \\
\end{array}$ & $\begin{array}{c}\text { Max } \\
\text { Tissue } \\
\text { Temp } \\
\left({ }^{\circ} \mathrm{C}\right) \\
\end{array}$ & $\begin{array}{c}\text { Bottom } \\
\text { Boundary } \\
\text { Temp } \\
\left({ }^{\circ} \mathrm{C}\right) \\
\end{array}$ \\
\hline \multicolumn{6}{|c|}{$20 \mathrm{~mm}$ Thick Tissue } \\
\hline$T=37^{\circ} \mathrm{C}$ & 7.53 & 11.18 & 65.65 & 99.85 & 37.00 \\
\hline $\begin{array}{c}T=15^{\circ} \mathrm{C}, h=1000 \\
W m^{-2} K^{-1}\end{array}$ & 7.47 & 11.10 & 68.55 & 99.95 & 17.37 \\
\hline $\begin{array}{c}T=15^{\circ} \mathrm{C} \\
h=2000 \mathrm{Wm}^{-2} \mathrm{~K}^{-1}\end{array}$ & 7.44 & 11.11 & 64.15 & 99.95 & 16.28 \\
\hline \multicolumn{6}{|c|}{$10 \mathrm{~mm}$ Thick Tissue } \\
\hline $\mathrm{T}=37^{\circ} \mathrm{C}$ & 8.012 & 12.01 & 65.35 & 104.45 & 37.00 \\
\hline $\begin{array}{c}T=15^{\circ} \mathrm{C}, h=1000 \\
\mathrm{Wm}^{-2} K^{-1}\end{array}$ & 6.767 & 11.24 & 64.25 & 101.95 & 20.38 \\
\hline $\begin{array}{c}T=15^{\circ} \mathrm{C} \\
h=2000 \mathrm{Wm}^{-2} \mathrm{~K}^{-1}\end{array}$ & 6.665 & 11.15 & 64.15 & 101.75 & 17.93 \\
\hline \multicolumn{6}{|c|}{$5 \mathrm{~mm}$ Thick Tissue } \\
\hline$T=37^{\circ} \mathrm{C}$ & 4.54 & 10.20 & 66.95 & 112.35 & 37.00 \\
\hline $\begin{array}{c}T=5^{\circ} \mathrm{C}, \\
h=2000 \mathrm{Wm}^{-2} \mathrm{~K}^{-1}\end{array}$ & 4.07 & 8.54 & 65.35 & 116.35 & 16.78 \\
\hline $\begin{array}{c}T=5^{\circ} \mathrm{C}, \\
h=20,000 \mathrm{Wm}^{-2} \mathrm{~K}^{-1}\end{array}$ & 3.85 & 8.29 & 65.75 & 127.55 & 6.95 \\
\hline $\begin{array}{c}T=-5^{\circ} \mathrm{C} \\
h=2000 \mathrm{Wm}^{-2} \mathrm{~K}^{-1}\end{array}$ & 3.99 & 8.10 & 60.15 & 116.85 & 8.85 \\
\hline $\begin{array}{c}T=-5^{\circ} \mathrm{C}, \\
h=20,0000 \mathrm{Wm}^{-2} K^{-1}\end{array}$ & 3.91 & 7.23 & 55.95 & 98.25 & -2.04 \\
\hline
\end{tabular}

TABLE III. COMPARING PRESENT RESUltS TO PREVIOUS EXPERIMENTAL WORK BY GONZÁLEZ-SUÁREZ AND BERJANO [26], 20 MM THICK TISSUE

\begin{tabular}{|c|c|c|c|}
\hline & $\begin{array}{c}\text { Previous } \\
\text { Work [26] }\end{array}$ & $\begin{array}{c}\text { Present } \\
\text { Results }\end{array}$ & $\begin{array}{c}\text { Percent } \\
\text { Difference (\%) }\end{array}$ \\
\hline Depth (mm) & 7.53 & 7.53 & 0 \\
\hline Width (mm) & 11.92 & 11.18 & 6.41 \\
\hline $\left.\mathbf{T}_{\text {max,tissue }}{ }^{\circ} \mathbf{C}\right)$ & 102.4 & 99.85 & 2.52 \\
\hline $\left.\mathbf{T}_{\text {max,blood }}{ }^{\circ} \mathbf{C}\right)$ & 79.9 & 65.65 & 19.58 \\
\hline
\end{tabular}

\section{Boundary Conditions}

The voltage boundary condition on the catheter was set to $25 \mathrm{~V}$ for a RF duration of $60 \mathrm{~s}$. The bottom face had a specified voltage of $0 \mathrm{~V}$. All remaining walls and interfaces were specified with zero electrical flux. Thermal boundary conditions were only specified on outside walls and on the bottom face. All outside walls were set at $37^{\circ} \mathrm{C}$. The bottom face was tested with a variety of boundary conditions including a constant temperature of $37^{\circ} \mathrm{C}$ and then various convective boundary conditions. All walls for the fluid domain were noslip and coupled with the adjoining material. The blood had a perpendicular laminar flow with an inlet velocity of $8.5 \mathrm{~cm} \cdot \mathrm{s}^{-1}$, and a zero-pressure outlet.

\section{Results}

Mesh convergence and time convergence were performed until the results were independent of both. The final step size was $0.05 \mathrm{~s}$ for $60 \mathrm{~s}$ and the final mesh had 419,362 elements with maximum and minimum face sizes of $1 \mathrm{~mm}$ and $4.99 \times 10^{-2} \mathrm{~mm}$, respectively. The lesion size was calculated using the $50^{\circ} \mathrm{C}$ isotherm for all models. Lesion depth is the maximum depth from the top of the tissue reached by the lesion and lesion width is the width of the isotherm at its widest point. All studies were run for sixty seconds. The key results can be seen in Table II and Fig. 2.

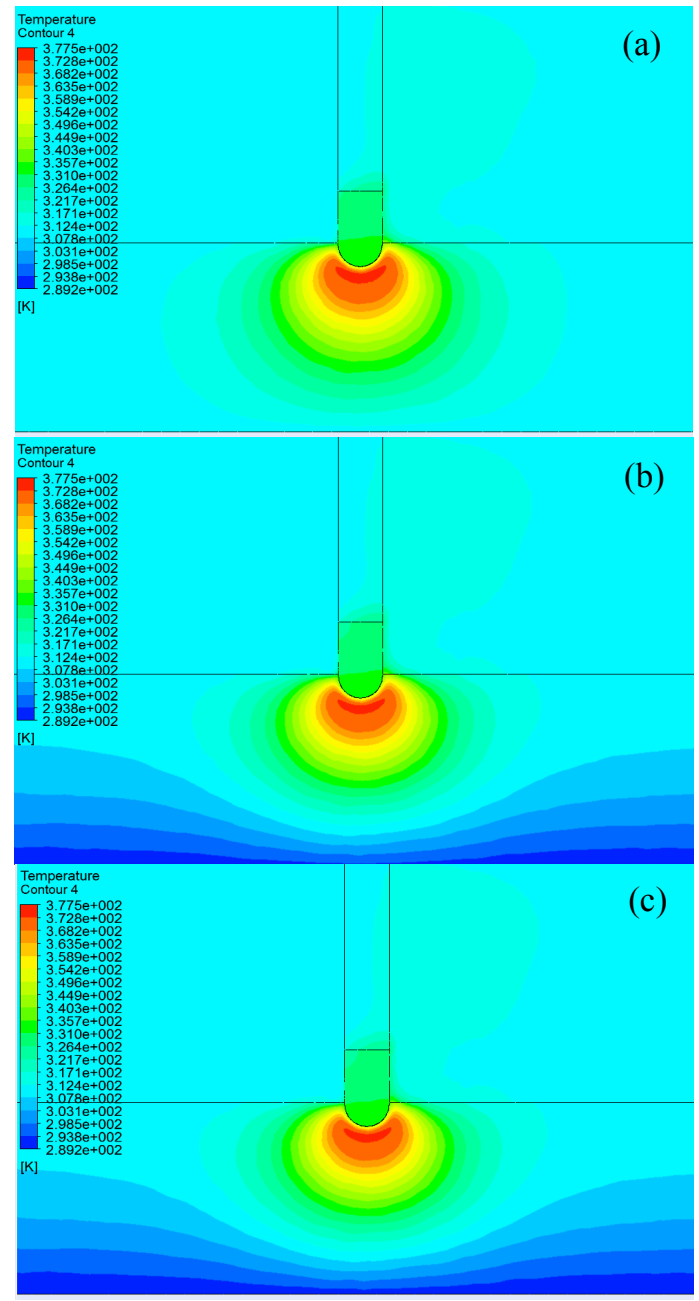

Figure 2. Results for $10 \mathrm{~mm}$ thick tissue. (a) $\mathrm{T}=37^{\circ} \mathrm{C}$ (b) $\mathrm{T}=15^{\circ} \mathrm{C}, \mathrm{h}=$ $1000 \mathrm{Wm}^{-2} \mathrm{~K}^{-1}$ (c) $\mathrm{T}=15^{\circ} \mathrm{C}, \mathrm{h}=2000 \mathrm{Wm}^{-2} \mathrm{~K}^{-1}$

For the $20 \mathrm{~mm}$ thick tissue the cooling had very little impact on lesion size due to the thickness of the tissue. The $37^{\circ} \mathrm{C}$ case was compared with that in González-Suárez and Berjano [26] for validation purposes in Table III. Maximal blood temperature is the only value that is significantly different, which is most likely due to a coarser mesh in the blood domain in the present model. The $10 \mathrm{~mm}$ thick tissue allowed for cooling to be much more effective in reducing lesion size. The lesion depth was reduced by a maximum of $18.4 \%$, the maximum tissue temperature was reduced by about $3{ }^{\circ} \mathrm{C}$, and the bottom boundary temperature was reduced by $69.4 \%$. The $5 \mathrm{~mm}$ tissue was affected the most by cooling as the lesion size was decreased by as much as $16.4 \%$.

\section{CONClusions AND Summary}

Previous models are, for the most part, experimentally validated; however, they do have some shortcomings. Most notably, the force applied to the catheter and the depth are only related in one published study. Another shortcoming is the lack of accurate blood flow modelling. To obtain an accurate representation of the real system, blood flow should be modelled as pulsatile and turbulent, and not by constant laminar flow or a convection coefficient. 
The computational results match previous data which have been verified using experimental data. The $5 \mathrm{~mm}$ thickness is representative of the total distance from catheter tip to inner esophageal wall [18] meaning the esophagus tissue and heart tissue layers were combined in this model. In future studies these two layers could be separated and have distinct properties as has been done in previous models [5]. The non-irrigated model demonstrates that regardless of tissue thickness cooling the esophageal wall has less than a $19 \%$ effect on the depth of the lesion, and as much as a $13.4 \%$ lowering of the temperature on the esophageal wall. This means that cooling on the esophageal wall can be used to effectively lower the damage to the esophagus without adversely affecting the procedure when a non-irrigated catheter is used. This model has temperatures that are too cool and would damage the esophagus, but the temperature of the cooling fluid or the convection coefficient can be easily changed. These results are in agreement with Berjano and Hornero [5], who also examined the effect of esophageal cooling. The present study demonstrates that cooling can be effectively added to the esophagus without comprising the RFA procedure.

\section{ACKNOWLEDGMENT}

This work was funded by Baylis Medical, the Natural Sciences and Engineering Research Council of Canada and MITACS. The guidance and support of Gareth Davies and Amanda Hartley of Baylis Medical is greatly appreciated.

\section{REFERENCES}

[1] Heart \& Stroke Foundation, "Atrial fibrilation," retrived from: http://www.heartandstroke.com/site/c.ikIQLcMWJtE/b.5052135/k.2C86 /Heart_disease_Atrial_fibrillation.htm on Dec. 1, 2017.

[2] S. Mohanty et. al, "Outcomes of atrioesophageal fistula following catheter ablation of atrial fibrillation treated with surgical repair versus esophageal stenting," in J. Cardio. Electrophysiology, vol. 25(6), pp. 579-584, 2014.

[3] C. Townsend, D. Beauchamp, M. Evers, and L. Kenneth, Sabiston Textbook of Surgery: The Biological Basis of Modern Surgical Practice. Elsevier Saunders, Philadelphia, pp. 236, 2012.

[4] A. González-Suárez, E. Berjano, J. Guerra, and L. Gerardo-Giorda, "Computational modeling of open-irrigated electrodes for radiofrequency cardiac ablation including blood motion-saline flow interaction," in PLoS ONE, vol. 11(3), pp. 1-18, 2016.

[5] E. Berjano, and F. Hornero, "A cooled intraesophageal balloon to prevent thermal injury during endocardial surgical radiofrequency ablation of the left Atrium: a finite element study," in Physics in Medicine and Biology, vol. 50(20), pp. N269-N279, 2005.

[6] J. Pérez, A. D'Avila, A. Aryana, and E. Berjano, "Electrical and thermal effects of esophageal temperature probes on radiofrequency catheter ablation of atrial fibrillation: results from a computational modeling study," in J. Cardio. Electrophysiology, vol. 26(5), pp. 556-564, 2015.

[7] D. Haines, and D. Watson, "Tissue heating during radiofrequency catheter ablation: a thermodynamic model and observations in isolated perfused and superfused canine right ventricular free wall," in Pacing and Clinical Electrophysiology, vol. 12(6), pp. 962-976, 1989.

[8] S. Labonté, "A theoretical study of radio-frequency ablation of the myocardium," Doctoral Thesis. University of Ottawa, 1992.

[9] S. Labonté, "A computer simulation of radio-frequency ablation of the endocardium," in IEEE Trans. Biomed. Eng., vol. 41(9), pp. 883-890, 1994.

[10] S. Labonté, and S. Stuchly, "Radio-frequency ablation of the myocardium: a numerical model," from the Annual International Conference of the IEEE Eng. in Medicine and Biology Society, vol. 13(2), pp. 619-620, 1991.
[11] J. Lequerica, E. Berjano, M. Herrero, and F. Hornero, "Reliability assessment of a cooled intraesophageal balloon to prevent thermal injury during RF cardiac ablation: an agar phantom study," in J. Cardiovascular Electrophysiology, vol. 19(11), pp. 1188-1193, 2008.

[12] F. Burdío et. al, "Research and development of a new RF-assisted device for bloodless rapid transection of the liver: computational modeling and in vivo experiments," in Biomed. Eng. Online, vol. 8: 6, 2009.

[13] J. Lopez, M. Rivera, and E. Berjano, "Analytical transient-time solution for temperature in non perfused tissue during radiofrequency ablation," in Applied Mathematical Modelling, vol. 42, pp. 618-635, 2017.

[14] A. Qadri, N. Chia, and E. Ooi, "Effects of saline volume on lesion formation during saline-infused radiofrequency ablation," in Applied Mathematical Modelling, vol. 43, pp. 360-371, 2017.

[15] H. Cao, M. Speidel, J. Tsai, M. Van Lysel, V. Vorperian, and J. Webster, "FEM analysis of predicting electrode-myocardium contact from RF cardiac catheter ablation system impedance," in IEEE Trans. on Biomedical Eng., vol. 49(6), pp. 520-526, 2002.

[16] M. Wood et. al, "Effect of electrode orientation on lesion sizes produced by irrigated radiofrequency ablation catheters," in J. of Cardio. Electrophysiology, vol. 20(11), pp. 1262-1268, 2009.

[17] R. Francés et. al, "Characterization of the impact of catheter-tissue contact force in lesion formation during cavo-tricuspid isthmus ablation in an experimental swine model," in Europace, vol. 16(11), pp. 1679-1683, 2014.

[18] F. Hornero, and E. Berjano, "Esophageal temperature during radiofrequency-catheter ablation of left atrium: a three-dimensional computer modeling study," in J. Cardio. Electrophysiology, vol. 17(4), pp. 405-410, 2006.

[19] I. Chang, "Considerations for thermal injury analysis for RF ablation devices," in the Open Biomedical Eng. J., vol. 4(2), pp. 3-12, 2010.

[20] E. Berjano, "Theoretical modeling for radiofrequency ablation: state-ofthe-art and challenges for the future," in Biomed. Eng. Online, vol. 5:24, 2006.

[21] D. Panescu, and J. Webster, "Effects of changes in electrical and thermal conductivities on radiofrequency lesion dimensions," from Proceedings of the IEEE International Conference of the Eng. in Medicine and Biology Society, vol. 154(1), pp. 154-156, 1997.

[22] M. Trujillo, and E. Berjano, "Review of the mathematical functions used to model the temperature dependence of electrical and thermal conductivities of biological tissue in radiofrequency ablation," in International J. of Hyperthermia, vol. 29(6), pp. 590-597, 2013.

[23] S. Lobo et. al, "RF tumour ablation: computer simulation and mathematical modelling of the effects of electrical and thermal conductivity," in International J. of Hyperthermia, vol. 21(3), pp. 199213, 2005.

[24] S. Quallich, K. Kriege, and P. Iaizzo, "The effects of radiofrequency or cryothermal ablation on biomechanical properties of isolated human or swine cardiac tissues," in IEEE J. of Translational Eng. in Health and Medicine, vol. 4, pp. 1-5, 2015.

[25] S. Tungjitkusolmun, E. Woo, H. Cao, J. Tsai, V. Vorperian, and J. Webster, "Thermal-electrical finite element modelling for radio frequency cardiac ablation: effects of changes in myocardial properties," in Medical \& Biological Eng. \& Computing, vol. 38, pp. 562-568, 2000.

[26] A. González-Suárez, and E. Berjano, "Comparative analysis of different methods of modeling the thermal effect of circulating blood flow during RF cardiac ablation," in IEEE Transactions on Biomed. Eng., vol. 63(2), pp. 250-259, 2016.

[27] J. Pearce, and S. Thomen, "Numerical models of RF ablation in myocardium," from IEEE International Conference of the Eng. in Medicine and Biology Society, and Canadian Medical and Biological Eng. Conference, vol. 7, pp. 269-270, 1995.

[28] D. Haines, D. Watson, and F. Verow, "Electrode radius predicts lesion radius during radiofrequency energy heating: validation of a proposed thermodynamic model," in Circulation Research, vol. 67(1), pp. 124-129, 1990. 